\title{
Demographic modelling helps tracking the rapid development of reproductive isolation between recently diverged conifers from central Mexico
}

\author{
Gustavo Giles-Pérez ${ }^{1}$, Erika Aguirre-Planter ${ }^{1}$, Luis Eguiarte ${ }^{1}$, and Juan Jaramillo-Correa ${ }^{1}$ \\ ${ }^{1}$ Instituto de Ecología, Universidad Nacional Autónoma de México
}

January 24, 2022

\begin{abstract}
Secondary contact of species that have evolved partial reproductive isolation in allopatry may result in several outcomes, which range from rampant hybridization to barrier reinforcement. Reinforcement arises from reduced hybrid fitness, which promotes assortative mating and hence speciation. In plants, self-fertilization and disjunction in reproductive phenology are often cited as evidence of reinforcement. However, local adaptation and pleiotropic effects during colonization can also lead to reproductive isolation without reinforcement. We explored these competing possibilities in a fir species complex (Abies flinckii - A. religiosa) distributed in 'sky-islands' along the Trans-Mexican Volcanic Belt (TMVB), in central Mexico. Despite co-occurring in two independent sympatric regions (west and center), these two taxa seem to rarely interbreed because of disjunct reproductive phenologies. We genotyped 1,147 SNPs, generated by GBS across 23 populations, and compared multiple demographic scenarios, built based on the geological history of the TMVB. The best-fitting model revealed one of the most rapid and complete speciation cases for a conifer species-pair, dating back to $\sim 1.2 \mathrm{Ma}$, which included an early asymmetric gene flow (mostly from A. flinckii into A. religiosa) limited to the most ancient sympatric region. Coupled with the lack of support for colonization models, our demographic inferences point to an early development of reinforcement, as a putative mechanism for avoiding hybridization. Reinforcement should be considered as a key player for originating and maintaining species diversity in the tropics and subtropics and incorporated in studies with other model systems.
\end{abstract}

\section{Hosted file}

Main_document.doc available at https : //authorea.com/users/412887/articles/553888-demographicmodelling-helps-tracking-the-rapid-development-of-reproductive-isolation-between-

recently-diverged-conifers-from-central-mexico 